\title{
Application of Cognitive-Behavioral Therapy in Obstructive Sleep Apnea: Comparison of Combined Treatment, and CPAP Therapy on Executive Functions of the Brain
}

\author{
Maryam Talebi ${ }^{1}$, Kazem Rasoolzadeh Tabatabaye ${ }^{2 \star}$, Ensiye Vahedi ${ }^{3}$ \\ ${ }^{1}$ PhD Student of Psychology, Department of Psychology, Faculty of Humanities, Tarbiat Modares University, Tehran, Iran, \\ ${ }^{2}$ Associate Professor, Tarbiat Modares University, Tehran, Iran \\ ${ }^{3}$ Pulmonary Disease Specialist, School of Medical Sciences, Baqiyatallah University of Medical Sciences, Tehran, Iran
}

\begin{abstract}
Purpose: Sleep apnea disorder brings about negative effects to the quality of life of the people involved. Debilitation of cognitive functioning is one of the consequences of this condition. However, scant researches have been carried out to explore the efficacy of cognitive therapy in mitigating the clinical symptoms and cognitive functions of the brain. Combining cognitive method and medical treatment, this research aims at comparing the effectiveness of continuous positive air pressure (CPAP) therapy and cognitive-behavioral treatment (CBT) in improving mental cognitive functions among patients with sleep apnea disorder.

Methods: The study population included all patients who referred to the sleep disorders clinic in Tehran. Our sample consisted of 45 subjects who were randomly allocated into three groups of 15 individuals (CPAP, combined treatment, and control). All three groups were psychologically assessed prior to the intervention. Next, individuals in the cognitive-behavioral group underwent CPAP and 12 sessions of cognitive training, progressive muscle relaxation, mental visualization, and sleep hygiene. The other group went through CPAP therapy and the third group was also assessed. After the intervention, all groups were again psychologically assessed. Data collection instruments included Wisconsin cognitive software, semantic and complex Stroop, continuous performance, and polysomnography and CPAP devices.

Results: The results indicated that both types of intervention can enhance cognitive functioning; however, a greater efficacy is obtained by combining the two methods compared with the exclusive application of medical treatment.

Conclusion: This research proposes cognitive-behavioral therapy as a complement to medical treatment.

Keywords: Obstructive sleep apnea, CPAP therapy, cognitive-behavioral therapy, cognitive functions
\end{abstract}

\section{INTRODUCTION}

Sleep as one of the most important natural and biological cycles of human beings is featured by a complex pattern. One normally applies the concept of sleep to refer to the

*Correspondence: rasoolza@Modares.ac.ir

Kazem Rasoolzadeh Tabatabaye, Associate professor, Tarbiat Modares University, Tehran, Iran Tel: 02182884616

Received: 28 July 2017 Accepted: 08 August 2017

Sleep and Hypnosis

Journal homepage:

www.sleepandhypnosis.org

ISSN:1302-1192 (Print) 2458-9101 (Online) effects associated with two circadian (24 hours) and balancing processes such as the adequacy of nocturnal sleep, sleep quantity, and daytime sleepiness.

Investigating sleep-related problems gains relevance for two reasons: First, such complaints are very common among people; second, low sleep quality is considered as an indicator of many psychological diseases (Ağargün, Kara, \& Anlar, 1996). In contrast, good quality sleep is a sign of mental and physical regeneration of individuals since cellular repair and mental health are dependent on sleep.

The quality and quantity of sleep also affect one's health, and these are always regarded as important factors 
influencing the quality of life. People with sleep disorder are not only characterized by fatigue, but also suffer from a range of complications like those related to cellular repair, defects in learning and memory, increased stress and anxiety, and reduced quality of daily life. Hence, sleep disorder can have detrimental effects on a person's health and improvement.

Sleep refers to a decreased level of consciousness, relative suspension of sensory perceptions, and inactivation of most voluntary muscles such that during sleep, bodily and mental activities change and visual hallucinations replace real sharp images. Sleep is often considered a source for restoring the energy spent in daytime. However, it has been proved that only between $5 \%$ to $10 \%$ of body's metabolism would decrease during sleep (Flemons et al., 1999).

Apnea is defined as the cessation of breathing, especially during sleep, which lasts for more than 10 seconds. Three types of apnea have been identified: obstructive sleep apnea (OSA), referring to the blockage of the upper airway; central sleep apnea (CSA), caused by brain problems; and mixed sleep apnea that combines the features of previous two types. The prevalence of sleep apnea in the general population is about $2-4 \%$. CSA is mostly found in older people, individuals with heart diseases, or those with stroke-related illnesses. CSA, which is less common, occurs when the brain cannot give order to the breathing muscles to start respiration. On the other hand, OSA, which is more common, happens when the air does not flow into or out of the nose and mouth, despite the efforts of an individual or his/her breathing muscles for respiration. The main cause of OSA can be attributed to the fact that tissues around the throat relax during sleep, fall on one another, and cause obstruction. This obstruction takes place at a faster pace in people who are affected by OSA compared with normal individuals. Mixed sleep apnea is a combination of the previous two types of apnea. OSA occurs more frequently in obese and middle-aged people, but it can happen at any age.

Appearing between two apnea attacks, snoring is more often than not associated with sleep apnea. Possibly, 20 to 30 apnea attacks occur per hour. In addition, patients may complain of choking during sleep, morning headaches and drowsiness, and daily dizziness. It is vital to diagnose and treat sleep apnea because the problem can lead to high blood pressure, stroke and heart attack, as well as heart and lung failure. If air does not enter or exit the lungs, one may be faced with an increase in the level of blood carbon dioxide and a decline in blood oxygen levels. These changes cause the person to wake up and as a result the throat muscle relaxation is reduced and the airway opens again allowing the air to flow. Even though such frequent awakenings perpetuate breathing, they deprive the patient from having a deep sleep. Sleep apnea is diagnosed in sleep laboratories with the help of polysomnogram, and can be treated using a variety of surgical and non-surgical procedures, depending on the severity and cause of the condition (Buysse, Reynolds, Kupfer, \& Thorpy, 1994).

Obstructive sleep apnea-hypopnea syndrome (OSAHS), which is the most common medical cause of drowsiness in daytime, is an important cause of disability and mortality around the globe. Nonetheless, CSA is far less prevalent than OSAHS. OSAHS refers to unexplained sleepiness during the day with at least 5 obstructive respiratory events per an hour of sleep. Apnea in adults denotes a respiratory suspension equal to or above 10 seconds. In the case of hypopnea, which again should last for 10 or more seconds, breathing continues and will not be interrupted; however, ventilation shrinks at least $40 \%$ compared with the previous sleep baseline (Durán, Esnaola, Rubio, \& Iztueta, 2001). In addition to clinical manifestations, certain abnormalities are associated with OSAHS, and asymptomatic patients who simply have an abnormal respiration during sleep should not be thought to have been affected by OSAHS. OSAHS prevalence in the general middle-aged male population is about $1 \%$ to $4 \%$ and is reduced by half in the case of women. This syndrome -usually associated with the enlargement of tonsils or adenoids- appears in both children and the elderly, yet it is less frequent in the latter group. Obstructive sleep apnea (OSA) is a common sleep disorder associated with excessive cognitive impairment.

According to some researchers, the first damage caused by poor sleep emerges in the ability of brain to plan and organize cognitive functions (Alhola \& Polo- 
Kantola, 2007). Sleep apnea is a common disorder with far-reaching implications for health and it is one of the major consequences of cognitive impairment (Lal, Strange, \& Bachman, 2012). Apnea leads to a negative effect on inductive and deductive reasoning, attention, alertness, learning (Incalzi et al., 2004), one's performance in the revised version of Wechsler Adult Intelligence Scale (Lal et al., 2012), psychomotor vigilance task (Dorrian, Rogers, \& Dinges, 2005; Gagnon et al., 2014), repetitive finger-tapping test (Lojander, Kajaste, Maasilta, \& Partinen, 1999) as well as impaired concentration, problem-solving, and verbal and spatial short-term memory (Findley et al., 1986). The prevalence of sleep apnea in adult men is about $3-7 \%$ and nearly $2-5 \%$ for adult women (Lindberg, 2010).

In addition to physical factors underlying sleep disorder, one can point to some psychological roots of this condition including emotional factors, dysfunctional beliefs and attitudes concerning sleep (Morin, Blais, \& Savard, 2002; Saunamäki \& Jehkonen, 2007), as well as behavioral factors such as inadequate sleep hygiene.

People with sleep apnea, due to frequent waking, are unable to enter the phase of rapid eye movement (REM), which is necessary for a good sleep (Iranzo \& Santamaria, 2005); therefore, they experience mental health problems such as anxiety and memory complications. This is because dreams are an opportunity for processing everyday events and a means of memory retention (Meyer, Sakai, Karacan, Derman, \& Yamamoto, 1980). They provide a ground for long-term goals, everyday interactions and discharge of anxious emotions.

Only a few studies have evaluated the behavioral interventions designed to improve CPAP use, with the findings somewhat equivocal. Cognitive behavioral approaches based on cognitive therapy have recently been applied to improve adherence to CPAP (Bandura, 1989). Cognitive theory relates to how humans think and choose. Perceptions and expectations derived from past experiences influence how a person acts. Similarly, provision of accurate information enhances new learning experiences and can correct irrational beliefs through exposure to positive stimuli (Bandura \& Walters, 1977). In this regard, recognizing the core beliefs is a key component that determines one's ability to accomplish future behaviors. To achieve this, realistic goals are set and positive experiences are shared by patients (real CPAP users) (Espie, Inglis, \& Harvey, 2001). Previous research with a small randomized intervention $(n=12)$ based on self-efficacy and decisional balance found improved adherence to CPAP (Richards, Bartlett, Wong, Malouff, \& Grunstein, 2007).

A cohort study on 4 million American soldiers revealed that 118 thousand individuals had gone through sleep apnea along with other disorders such as depression (21.8\%), post-traumatic stress (11.9\%) anxiety (16.7\%), psychosis (5.1\%), and bipolar disorder (3.3\%) (Sharafkhaneh, Giray, Richardson, Young, \& Hirshkowitz, 2005; Sharafkhaneh, Richardson, \& Hirshkowitz, 2004).

Bardwell et al. (2003) reported that after controlling severe sleep apneas, the subjects showed symptoms of depression and fatigue. Hence, they suggested that in addition to controlling this disorder, one has to take psychological symptoms and mood complications into account as well (Bardwell, Moore, Ancoli-Israel, \& Dimsdale, 2003). It is worth noting that depression causes the most prevalent conditions in subjects with sleep apnea (Baran \& Richert, 2003).

It is also shown that anxiety and depression decrease as a result of continuous positive air pressure (CPAP), but fatigue might be still there and the treatment may not improve it. In fact, intense apnea disorder is associated with the increase of anxiety and depression.

Aloia et al. (2003) in their research on the cognitive effects of apnea and treatment with continuous positive air pressure demonstrated that consciousness increases after treatment, but there still remains a weakness in terms of cognitive abilities and mental performance. In other words, many cognitive deficiencies cannot be compensated by medical care alone (Aloia, Arnedt, Stepnowsky, Hecht, \& Borrelli, 2005).

In their follow-up study, Bourke et al. (2011) observed a decrease in the level of anxiety, depression, and psychological distress after treatment; nevertheless, not that much improvement was found in cognitive function tests. Such improvement requires a longer treatment period (Bourke et al., 2011). Bourke reported that some 
cognitive symptoms can be treated but this will not lead to improvement in mood and affection symptoms (Bourke et al., 2011). The use of ECT after treatment by CPAP is evidence indicating that some of the cognitive functions and symptoms (e.g. depression) cannot be completely improved through CPAP. After treatment with CPAP, the symptoms of mental weakness (psychasthenia), evaluated by MMPI-2 test, remained unchanged (Saunamäki \& Jehkonen, 2007).

In their samples who were treated with CPAP and were mentally trained, Golay et al. (2006) also observed a considerable progress in improved quality of life compared to the group without training (Golay et al., 2006). The faith-based model to health, which emphasizes patients' mental experience of health and their beliefs, produces more stable treatment effects (Tyrrell, Poulet, $\mathrm{Pe}, \&$ Veale, 2006).

Therefore, due to the severity of cognitive side effects and considering the important role of cognitive disabilities in the course of this condition, we employed, in addition to medical treatment, the cognitive-behavioral approach as a combination therapy to improve executive functions of patients.

\section{MATERIALS AND METHODS}

This case study is a quasi-experimental research with pretest and post-test design and a control group. Research population included 270 patients who referred to sleep disorders clinics in Tehran in 2016.To conduct the study, 45 patients with sleep apnea were chosen using purposive sampling and were assigned to control and experimental groups. The participants' demographic and clinical data are presented in Table 1.
The criteria for inclusion were as follows: maximum age of 60 years, no psychotic and personality disorder, no substance abuse, lack of sleep medications, observing ethical principles, and willingness to cooperate. Under the supervision of a psychiatrist and with the assistance of the clinical psychologist, we applied, using Wisconsin Card Sorting Test, the semantic and complex Stroop, together with continuous performance task, the relevant components of executive functions to clients whose apnea had been diagnosed using polysomnography device.

CBT-I was administered in a group setting with an experienced psychologist. Treatment lasted for seven sessions ( $90_{\text {mins }}$ each) over 9 weeks, and in each session we taught some psychological methods to our patients, including standard CBT-I and sleep hygiene, stimulus control, relaxation techniques, and sleep restriction.

In polysomnography, the following variables were systematically monitored: electroencephalogram (C3/ A2, C4/A1, Fpz/ A1-A2, O1/A1), 2 electro-oculograms (right and left eye), chin and leg electromyograms, electrocardiogram (modified V2 lead), and a body position sensor. Respiration was monitored with a nasal cannula pressure transducer, an oral thermistor, a neck microphone, thoracic and abdominal piezoelectric belts, and finger pulse oximetry. The severity of OSA was determined through the results of the PSG.

CPAP is an accepted treatment that improves neurocognitive performance and survival rates (McFadyen, Espie, McArdle, Douglas, \& Engleman, 2001). However, the treatment has high efficacy but low effectiveness, with refusal rates for adherence ranging from $5 \%$ to $50 \%$ in the first week to 6 months (Engleman

Table 1. Demographic and clinical characteristics of study subjects with OSAD and controls

\begin{tabular}{lccc}
\hline Components & Combination & Medical & Control \\
\hline Age & $48.42 \pm 6.24$ & $46.32 \pm 7.44$ & $47.91 \pm 9.51$ \\
Gender (M/F) & $(7.8)$ & $(4.11)$ & $(6.9)$ \\
BMI & $29.42 \pm 5.90$ & $29.67 \pm 5.20$ & $29.84 \pm 5.31$ \\
Hypertension (n (\%)) & $5(16.7 \%)$ & $4(15.2 \%)$ & 0 \\
Coronary heart disease & $1(3.3 \%)$ & $1.2(3.5 \%)$ & 0 \\
Hypercholesterolemia (n (\%)) & $5(16.7 \%)$ & $6(17.7 \%)$ & 0 \\
Mean hours used/night & $5 \mathrm{~h} .20 \pm 1.35$ & $6 \mathrm{~h} .10 \pm 1.32$ & $5 \mathrm{~h} .40 \pm 1.27$ \\
\hline
\end{tabular}


\& Wild, 2003). Continued CPAP usage is best associated by reduced somnolence (Engleman et al., 1996).

\section{RESULTS}

Table 2 provides the average pretest and post-test scores in the experimental and control groups. As can be seen, compared with the control group, the post-test scores of the experimental groups have been improved in all indices.

To examine the differences in the linear combination of dependent variables in the experimental and control groups, we drew on Wilks' Lambda multivariate test (Table 3). The results of all four tests showed that after

Table 2. Mean and SD of research variables in three groups in the pretest and post-test

\begin{tabular}{|c|c|c|c|c|c|c|c|}
\hline \multirow{2}{*}{ Variables } & \multirow{2}{*}{ Components } & \multicolumn{2}{|c|}{ Combination Group } & \multicolumn{2}{|c|}{ Medical Group } & \multicolumn{2}{|c|}{ Control Group } \\
\hline & & Pre-test & Post-test & Pre-test & Post-test & Pre-test & Post-test \\
\hline \multirow{12}{*}{ Stroop Test } & Correct answers & 0.74 & 0.64 & 0.59 & 0.63 & 0.67 & 0.64 \\
\hline & (phase 1) & 9.13 & 9.53 & 9.26 & 9.40 & 9.20 & 9.13 \\
\hline & Correct answers & 0.53 & 0.63 & 0.59 & 0.60 & 0.59 & 0.53 \\
\hline & (phase 2) & 9.00 & 9.40 & 9.06 & 9.26 & 9.07 & 9.02 \\
\hline & Correct answers & 0.41 & 0.50 & 0.51 & 0.59 & 0.59 & 0.56 \\
\hline & (phase 3) & 8.80 & 9.41 & 8.86 & 9.07 & 8.73 & 8.80 \\
\hline & Reaction time & 0.18 & 0.16 & 0.19 & 0.17 & 0.18 & 0.16 \\
\hline & (phase 1) & 0.98 & 0.87 & 0.97 & 0.93 & 1.00 & 1.00 \\
\hline & Reaction time & 0.14 & 0.13 & 0.17 & 0.14 & 0.16 & 0.15 \\
\hline & (phase 2) & 0.90 & 0.80 & 0.91 & 0.85 & 0.94 & 0.92 \\
\hline & Reaction time & 0.19 & 0.16 & 0.18 & 0.16 & 0.17 & 0.13 \\
\hline & (phase 3) & 1.02 & 0.90 & 1.03 & 0.97 & 1.03 & 1.02 \\
\hline \multirow{8}{*}{ Emotional Stroop test } & Correct answers & 32.06 & 35.66 & 32.00 & 33.40 & 31.66 & 31.60 \\
\hline & (list of related words) & 2.65 & 1.95 & 2.97 & 2.09 & 2.74 & 2.38 \\
\hline & Correct answers & 30.93 & 34.40 & 30.73 & 32.80 & 30.80 & 31 \\
\hline & (list of unrelated words) & 2.57 & 1.29 & 2.63 & 2.11 & 2.30 & 1.77 \\
\hline & Reaction time & 0.11 & 0.08 & 0.14 & 0.11 & 0.12 & 0.10 \\
\hline & (list of related words) & 0.89 & 0.83 & 0.89 & 0.86 & 0.91 & 0.90 \\
\hline & Reaction time & 0.08 & 0.06 & 0.11 & 0.09 & 0.12 & 0.11 \\
\hline & (list of unrelated words) & 0.90 & 0.83 & 0.88 & 0.85 & 0.89 & 0.88 \\
\hline \multirow{6}{*}{ Performance test } & Average reaction time & 0.08 & 0.06 & 0.07 & 0.05 & 0.09 & 0.06 \\
\hline & & 0.85 & 72.0 & 0.84 & 0.78 & 0.85 & 0.84 \\
\hline & Error of commission & 0.68 & 0.77 & 1.27 & 0.74 & 0.97 & 0.64 \\
\hline & & 4.80 & 3.20 & 4.73 & 3.86 & 4.66 & 4.46 \\
\hline & Error of omission & 0.64 & 0.74 & 0.70 & 0.63 & 0.70 & 0.91 \\
\hline & & 3.86 & 2.46 & 4.06 & 3.40 & 3.93 & 3.86 \\
\hline \multirow{10}{*}{$\begin{array}{c}\text { Wisconsin } \\
\text { Classification Test }\end{array}$} & Completed classes & 1.09 & 1.12 & 1.03 & 1.26 & 0.72 & 0.59 \\
\hline & & 4.06 & 5.46 & 4.26 & 5.20 & 4.33 & 4.26 \\
\hline & Preservation error & 12.20 & 10.40 & 12.13 & 11.20 & 13 & 13 \\
\hline & & 3.43 & 2.09 & 3.27 & 2.30 & 2.72 & 1.92 \\
\hline & Other errors & 13.06 & 8.20 & 12.80 & 10.13 & 12.86 & 12.73 \\
\hline & & 4.36 & 2.21 & 4.69 & 3.54 & 3.55 & 2.25 \\
\hline & Failure to maintain & 0.12 & 0.09 & 0.13 & 0.12 & 0.12 & 0.07 \\
\hline & a sequence & 0.79 & 0.55 & 0.81 & 0.68 & 0.81 & 0.80 \\
\hline & Attempt to complete & 18.33 & 14.66 & 17.73 & 15.53 & 19.06 & 18.46 \\
\hline & the first pattern & 7.79 & 5.88 & 6.18 & 4.40 & 5.94 & 4.74 \\
\hline
\end{tabular}

Table 3. Multivariate tests (Wilks' Lambda statistics)

\begin{tabular}{|c|c|c|c|c|c|}
\hline Test & Value & $\mathbf{F}$ & Df. & Sig. & Eta. \\
\hline Stroop & .133 & 8.996 & 12 & .000 & .635 \\
\hline Emotional Stroop & .105 & 18.210 & 8 & .000 & .675 \\
\hline Performance & .122 & 22.940 & 6 & .000 & .650 \\
\hline Wisconsin Classification & .110 & 13.270 & 10 & .000 & .668 \\
\hline
\end{tabular}


Table 4. Intergroup effect test

\begin{tabular}{|c|c|c|c|c|c|c|}
\hline Variables & Dependent Variable & SS & Df. & $\mathbf{F}$ & Sig. & Eta \\
\hline \multirow{6}{*}{ Stroop Test } & $\begin{array}{c}\text { Correct answers } \\
\text { (phase 1) }\end{array}$ & 1.574 & 2 & 3.586 & .038 & .166 \\
\hline & $\begin{array}{l}\text { Correct answers } \\
\text { (phase 2) }\end{array}$ & 1.485 & 2 & 2.745 & .078 & .132 \\
\hline & $\begin{array}{l}\text { Correct answers } \\
\text { (phase 3) }\end{array}$ & 2.669 & 2 & 4.963 & .012 & .216 \\
\hline & $\begin{array}{c}\text { Reaction time } \\
\text { (phase 1) }\end{array}$ & 273.455 & 2 & 21.672 & .000 & .546 \\
\hline & $\begin{array}{l}\text { Reaction time } \\
\quad \text { (phase 2) }\end{array}$ & 229.316 & 2 & 27.528 & .000 & .605 \\
\hline & $\begin{array}{l}\text { Reaction time } \\
\quad \text { (phase 3) }\end{array}$ & 303.672 & 2 & 52.080 & .000 & .743 \\
\hline \multirow{4}{*}{ Emotional Stroop test } & $\begin{array}{c}\text { Correct answers } \\
\text { (list of related words) }\end{array}$ & 111.481 & 2 & 54.602 & .000 & .742 \\
\hline & $\begin{array}{l}\text { Correct answers } \\
\text { (list of unrelated words) }\end{array}$ & 83.941 & 2 & 32.107 & .000 & .628 \\
\hline & $\begin{array}{l}\text { Reaction time } \\
\text { (list of related words) }\end{array}$ & 106.698 & 2 & 25.907 & .000 & .577 \\
\hline & $\begin{array}{c}\text { Reaction time } \\
\text { (list of unrelated words) }\end{array}$ & 106.828 & 2 & 28.547 & .000 & .600 \\
\hline \multirow{3}{*}{ Performance test } & Average reaction time & 406.849 & 2 & 74.160 & .000 & .792 \\
\hline & Error of commission & 13.348 & 2 & 23.476 & .000 & .546 \\
\hline & Error of omission & 14.441 & 2 & 11.719 & .000 & .375 \\
\hline \multirow{5}{*}{$\begin{array}{c}\text { Wisconsin } \\
\text { Classification test }\end{array}$} & Completed classes & 12.580 & 2 & 7.773 & .000 & .296 \\
\hline & Preservation error & 36.877 & 2 & 14.226 & .000 & .435 \\
\hline & Other errors & 159.161 & 2 & 57.396 & .000 & .756 \\
\hline & Failure to maintain a sequence & .408 & 2 & 56.619 & .000 & .754 \\
\hline & $\begin{array}{l}\text { Attempt to complete } \\
\text { the first pattern }\end{array}$ & 79.667 & 2 & 24.189 & .000 & .567 \\
\hline
\end{tabular}

controlling the pretest factor, there was a significant difference in the linear combination of dependent variables; hence, the group factor was seen to have a significant impact.

Table 4 illustrates the results of intergroup effect test which can be used to examine the differences between each dependent variable. The results of Table 4 show that the mean scores of post-test have been significantly changed in all of the dependent variables except for the index of "correct responses (phase 2)".

Having observed that $F$ value has been significant in all of the related indices except for that of "correct answers (phase 2)," we next used Bonferroni post hoc test for the other 17 indices whose $F$ value were significant in order to determine those post-test scores of the groups that had gone through significant changes. In other words, Bonferroni test was employed so as to make a mutual comparison between the experimental and control groups.
The tables in the attachment concern apnea hypopnea index, PLMS index score, O2 saturation index, polysomnography results of the duration and quality of sleep, respiratory events, oximetry, snoring and arousal index, and PLMD in the case and control groups.

After ascertaining that the three groups had a normal distribution in terms of sleep efficacy (as shown by KS test), we used independent samples t-test to compare the results. It was revealed that the average sleep efficacy of the three groups have a significant difference. $(P<0.05)$

Since KS test did not provide a normal SOL distribution, Mann-Whitney test was instead deployed to compare the results. Accordingly, no significant difference was seen in the average SOL of the three groups $(p=$ 0.400).

Because OSA of the three groups was normal on the basis of KS test $(p<0.05)$, T test was utilized to compare the three OSAs. The results suggest a significant difference 
Table 5. Bonferroni test comparing post-test mean of the indices studied in the three groups

\begin{tabular}{|c|c|c|c|c|c|c|c|}
\hline \multirow[t]{2}{*}{ Variables } & \multirow{2}{*}{$\begin{array}{c}\text { Components } \\
\begin{array}{c}\text { Correct answers } \\
\text { (phase 1) }\end{array}\end{array}$} & \multicolumn{2}{|c|}{$\begin{array}{l}\text { Comparison of } \\
\text { Combination therapy with } \\
\text { medical treatment }\end{array}$} & \multicolumn{2}{|c|}{$\begin{array}{c}\text { Comparison of medical } \\
\text { treatment with control } \\
\text { group }\end{array}$} & \multicolumn{2}{|c|}{$\begin{array}{c}\text { Comparison of } \\
\text { Combination therapy with } \\
\text { control group }\end{array}$} \\
\hline & & Sig. & $\begin{array}{c}\text { Mean } \\
\text { Difference }\end{array}$ & Sig. & $\begin{array}{c}\text { Mean } \\
\text { Difference }\end{array}$ & Sig. & $\begin{array}{c}\text { Mean } \\
\text { Difference }\end{array}$ \\
\hline \multirow{5}{*}{ Stroop Test } & $\begin{array}{l}\text { Correct answers } \\
\text { (phase 2) }\end{array}$ & .727 & .206 & .442 & .261 & .034 & .467 \\
\hline & $\begin{array}{l}\text { Correct answers } \\
\text { (phase } 3 \text { ) }\end{array}$ & .166 & .380 & .802 & .220 & .011 & .600 \\
\hline & $\begin{array}{l}\text { Reaction time } \\
\quad(\text { phase 1) }\end{array}$ & .001 & 059.- & .030 & 042.- & .000 & 102.- \\
\hline & $\begin{array}{l}\text { Reaction time } \\
\quad \text { (phase 2) }\end{array}$ & .005 & 042.- & .001 & 051.- & .000 & 094.- \\
\hline & $\begin{array}{l}\text { Reaction time } \\
\quad \text { (phase 3) }\end{array}$ & .000 & 065.- & .001 & 041.- & .000 & 107.- \\
\hline \multirow{4}{*}{$\begin{array}{l}\text { Emotional } \\
\text { Stroop test }\end{array}$} & $\begin{array}{c}\text { Correct answers } \\
\text { (list of related words) }\end{array}$ & .000 & 2.328 & .000 & 1.598 & .000 & 3.926 \\
\hline & $\begin{array}{l}\text { Correct answers } \\
\text { (list of unrelated }\end{array}$ & .002 & 1.583 & .000 & 1.841 & .000 & 3.424 \\
\hline & $\begin{array}{l}\text { Reaction time } \\
\text { (list of related words) }\end{array}$ & .002 & 033.- & .002 & 031.- & .000 & 064.- \\
\hline & $\begin{array}{c}\text { Reaction time } \\
\text { (list of unrelated words) }\end{array}$ & .000 & 036.- & .006 & 028.- & .000 & 064.- \\
\hline \multirow{3}{*}{ Performance test } & Average reaction time & .000 & $.067-$ & .000 & $.055-$ & .000 & 123.- \\
\hline & Error of commission & .003 & -.712 & .008 & -.628 & .000 & -1.339 \\
\hline & Error of omission & .013 & -.881 & .275 & -.497 & .000 & -1.378 \\
\hline
\end{tabular}

Table 6. Apnea hypopnea index

\begin{tabular}{cccc}
\hline AHI & $\begin{array}{c}\text { Combined } \\
\text { treatment }\end{array}$ & CPAP & Control \\
\hline $5-15$ & $29 \%$ & $37 \%$ & $34 \%$ \\
$15-30$ & $33 \%$ & $35 \%$ & $29 \%$ \\
$>30$ & $20 \%$ & $42 \%$ & $38 \%$ \\
\hline
\end{tabular}

in the average OSA of the groups ( $p>0.05)$. Given that CSA of the three groups was not normal as indicated by KS test $(p<0.05)$, we employed Mann-Whitney test in order to compare the three CSAs. Based on the conducted tests, no significant difference was observed in the average CSA of the two groups ( $p>0.05$ ).

Since MSA of the three groups was not normal as demonstrated by KS test ( $p<0.05)$, Mann-Whitney test was chosen to compare MSA of the two cases and control groups. The tests did not, however, show a significant difference in the average MSA of the two groups ( $p>0.05$ ).

After it was indicated that the three groups had a normal hypopnea distribution (as shown by KS test), we used independent samples t-test to compare the results
Table 7. PLMS index score

\begin{tabular}{cccc}
\hline PLMS & $\begin{array}{c}\text { Combined } \\
\text { treatment }\end{array}$ & CPAP & Contol \\
\hline$>20$ & $85 \%$ & $79 \%$ & $74 \%$ \\
$<20$ & $15 \%$ & $21 \%$ & $26 \%$ \\
\hline
\end{tabular}

Table 8. O2 saturation index

\begin{tabular}{ccccc}
\hline $\begin{array}{c}\text { Average O2 } \\
\text { saturation }\end{array}$ & $\begin{array}{c}\text { Combined } \\
\text { treatment }\end{array}$ & CPAP & Control & P value \\
\hline $\begin{array}{c}\text { 90-95 mild } \\
\text { hypoxia }\end{array}$ & $22 \%$ & $25 \%$ & $19 \%$ & 0.02 \\
$\begin{array}{c}\mathbf{8 5 - 9 0} \text { moderate } \\
\text { hypoxia } \\
\text { <85 seve } \\
\text { hypoxia }\end{array}$ & $43 \%$ & $39 \%$ & $47 \%$ & 0.001 \\
\hline
\end{tabular}

of the three groups, and it was proven that the average number of hypopneas of the three groups did not have a significant difference ( $p>0.05)$. Similarly, once the normal distribution of $\mathrm{AHI}$ of the three groups was observed (using KS test), independent samples t-test was employed to compare the results. Accordingly, a significant 
difference was noted in the average $\mathrm{AHI}$ of the three groups ( $p>0.05)$.

Since RDI of the three groups was not normal (as shown by KS test) $(p<0.05)$, Mann-Whitney test was used to compare the results. The tests did not, however, show a significant difference in the average RDI of the three groups ( $p>0.05$ ).

Since KS test did not show a normal average of $\mathrm{O} 2$ saturation for the two groups ( $p<0.05)$, Mann-Whitney test was used to compare the average $\mathrm{O} 2$ saturation. This time, however, the tests revealed a significant difference in the average $\mathrm{O} 2$ saturation of the three groups $(p=0.047)$. Because KS test did not yield a normal average for the lowest $\mathrm{O} 2$ saturation of the groups $(p<0.05)$,
Mann-Whitney test was used to compare the average lowest $\mathrm{O} 2$ saturation in the three groups. Nevertheless, the tests displayed a significant difference in the average lowest $\mathrm{O} 2$ saturation of the three groups ( $>0.05)$.

When it became clear that the three groups had a normal distribution in terms of average desaturation (as indicated by KS test), independent samples t-test was applied to compare the results of the three groups. It was understood, however, that average desaturation of the two groups have a significant difference $(p>0.05)$.

Owing that KS test did not show a normal average of snoring in the three groups $(p<0.05)$, we used MannWhitney test in order to compare this variable in the three groups. Also, considering that KS test did not obtain

Table 9. Polysomnography results of the duration and quality of Sleep in the case and control groups

\begin{tabular}{lcccc}
\hline \multirow{2}{*}{ Variables } & \multicolumn{3}{c}{ Mean \pm SD } & P value \\
\cline { 2 - 4 } & Combined treatment & CPAP & Control group & \\
\hline Sleep onset latency (min.) & $21.40 \pm 19.91$ & $19.20 \pm 13.62$ & $13.29 \pm 16.91$ & 0.400 \\
Sleep quality (\%) & $84.77 \pm 10.62$ & $82.36 \pm 10.43$ & $79.91 \pm 10.33$ & 0.0561 \\
S1 Phase (\%) & $15.96 \pm 17.73$ & $17.65 \pm 16.42$ & $23.85 \pm 18.81$ & $0.016^{\star}$ \\
S2 Phase (\%) & $52.42 \pm 16.87$ & $53.17 \pm 13.81$ & $55.15 \pm 14.36$ & 0.001 \\
S3 Phase (\%) & $22.80 \pm 14.62$ & $17.94 \pm 13.02$ & $14.87 \pm 10.61$ & 0.148 \\
REM Phase (\%) & $11.15 \pm 7.52$ & $10.18 \pm 7.52$ & $7.25 \pm 7.52$ & $0.003^{\star}$ \\
Number of REM & $3.77 \pm 1.62$ & $4.4 \pm 1.96$ & $3.21 \pm 1.58$ & 0.185 \\
REM onset latency (min.) & $121.67 \pm 69.21$ & $110.02 \pm 62.43$ & $108.12 \pm 58.40$ & 0.974 \\
\hline
\end{tabular}

Note. $\mathrm{P}<0.05$ values were considered significant.

Table 10. Polysomnography results of respiratory events in the case and control groups

\begin{tabular}{lcccc}
\hline & \multicolumn{3}{c}{ Mean \pm SD } & \multicolumn{1}{c}{ P value } \\
\cline { 2 - 4 } Variables & $\begin{array}{c}\text { Combined } \\
\text { treatment }\end{array}$ & CPAP & Control group \\
\hline Obstructive Sleep Apnea (N) & $16.51 \pm 30.85$ & $22.43 \pm 32.74$ & $24.89 \pm 37.63$ & 0.004 \\
Central Sleep Apnea (N) & $10.63 \pm 23.63$ & $7.02 \pm 14.08$ & $6.10 \pm 11.38$ & 0.068 \\
Mix Sleep Apnea (N) & $3.94 \pm 8.03$ & $4.04 \pm 9.02$ & $6.02 \pm 12.96$ & 0.050 \\
Hypopneas (N) & $64.35 \pm 48.37$ & $67.30 \pm 43.08$ & $60.70 \pm 41.55$ & 0.079 \\
Apnea-Hypopnea Index (Number/hour) & $17.93 \pm 17.24$ & $15.65 \pm 12.13$ & $16.48 \pm 12.38$ & 0.053 \\
Respiratory Disturbance index (Number/hour) & $27.03 \pm 24.40$ & $26.09 \pm 23.08$ & $27.63 \pm 25.05$ & 0.024 \\
\hline
\end{tabular}

Note. $P<0.05$ values were considered significant.

Table 11. Polysomnography results of oximetry in the case and control groups

\begin{tabular}{lcccc}
\hline & \multicolumn{4}{c}{ Mean \pm SD } \\
\cline { 2 - 4 } Variables & $\begin{array}{c}\text { Combined } \\
\text { treatment }\end{array}$ & CPAP & Control group & P value \\
\hline Average O2 saturation (\%) & $92.05 \pm 3.21$ & $91.08 \pm 3.09$ & $92.83 \pm 2.95$ & 0.047 \\
The lowest O2 saturation (\%) & $81.63 \pm 9.21$ & $82.09 \pm 10.71$ & $81.83 \pm 12.98$ & 0.031 \\
Oxygen desaturation (N/h) & $28.04 \pm 26.99$ & $25.04 \pm 32.73$ & $31.79 \pm 34.35$ & 0.038 \\
\hline
\end{tabular}

Note. $\mathrm{P}<0.05$ values were considered significant 
Talebi / Sleep and Hypnosis 2018

Table 12. Polysomnography results of Snoring and arousal index in the case and control groups

\begin{tabular}{lcccc}
\hline \multirow{2}{*}{ Variables } & \multicolumn{3}{c}{ Mean \pm SD } & P value \\
\cline { 2 - 4 } & $\begin{array}{c}\text { Combined } \\
\text { treatment }\end{array}$ & CPAP & Control group & \\
\hline Snoring (N) & $175.28 \pm 267.24$ & $165.29 \pm 143.63$ & $104.37 \pm 122.79$ & 0.206 \\
Arousal index (Number/ hour) & $20.65 \pm 22.35$ & $25.43 \pm 21.10$ & $29.48 \pm 20.10$ & $0.005^{\star}$ \\
Respiration-related arousal & $15.85 \pm 33.29$ & $24.69 \pm 35.73$ & $27.24 \pm 38.00$ & 0.454 \\
\hline
\end{tabular}

Note. $P<0.05$ values were considered significant

Table 13. Polysomnography results of PLMD in the case and control groups

\begin{tabular}{lcccc}
\hline & \multicolumn{3}{c}{ Mean \pm SD } & P value \\
\cline { 2 - 4 } Variables & $\begin{array}{c}\text { Combined } \\
\text { treatment }\end{array}$ & CPAP & Control group & \\
\hline PLM arousal index (Number/h) & $19.29 \pm 19.30$ & $20.08 \pm 17.20$ & $22.13 \pm 22.24$ & 0.002 \\
Respiration-related PLM index (Number) & $22.29 \pm 59.17$ & $21.29 \pm 39.38$ & $20.63 \pm 42.84$ & 0.035 \\
PLM index (Number/hour) & $30.65 \pm 38.45$ & $35.36 \pm 65.58$ & $38.59 \pm 64.68$ & 0.002 \\
\hline
\end{tabular}

Note. $\mathrm{P}<0.05$ values were considered significant

a normal average in the arousal index of the two groups ( $p$ < 0.05), we used Mann-Whitney test in order to compare arousal index of the three groups; and it was observed that there was a significant difference in the average arousal index $(p=0.005)$.

Since average PLMS with arousal was not normal in the three groups (as shown by KS test) $(p<0.05)$, we made use of Mann-Whitney test to compare PLMS with arousal in the two groups; after which it was seen that there was a significant difference in the average PLMS with arousal

Given that the average PLMS with respiratory event of the two groups was not normal (as indicated by KS test) $(p<0.05)$, we used Mann-Whitney test to compare PLMS with respiratory event of the three groups. Accordingly, significant difference was noted in the average PLMS with respiratory event $(p=0.035)$. By the same token, as KS test did not give a normal average for PLMS index of the three groups ( $p<0.05)$, Mann-Whitney test was implemented so as to make a comparison between PLMS index of the three groups. The results, however, indicated a significant difference in the average PLMS index.

\section{DISCUSSION}

The main purpose of this study was to investigate the effect of combination therapy in improving the cognitive skills of patients. Regarding the two indices of "correct answers (phase 1)" and "correct answers (phase 2)," it was found that the mean for combined treatment group was significantly higher than that of control group; however, there was no significant difference between the medical treatment and control group. Therefore, compared to medical treatment, combined treatment was more effective on the indices of "correct answers (phase 1)" and "correct answers (phase 2). Nevertheless, it has to be noted that there was no significant difference between the mean of post-tests in the combined treatment and medical treatment groups. As for the indices of "reaction time (phase 1)," "reaction time (phase 2)," and "reaction time (phase 3)," it was indicated that both combined treatment and medical treatment had a significant impact, compared to the control group, and led to the improved performance of the subjects. Specifically, combined treatment showed a significantly better effect than medical treatment in the case at hand. Regarding the four indices of "correct answers (list of related words)," "correct answers (list of unrelated words), "reaction time (list of related words)," and "reaction time (list of unrelated words)," we observed that both combined treatment and medical treatment displayed a significant effect, compared to the control group, and they clearly improved subjects' performance. 
Moreover, it was remarkable that combined treatment had a significantly better effect than medical treatment. Based on the indices of "average reaction time," "commission error," and "omission error," subjects" performance was better in both experimental groups than in the control group. Besides, combined treatment revealed a significantly greater performance than medical treatment.

This is in line with the results obtained by Nejati et al. (2012) based on which meditation and mindfulness helps the regulation of emotional states and increases activity in the forehead while decreasing it in amygdala and insole areas. However, in Mohlman and Gorman's study (2005), the amount of error and response time of the subjects decreased with increased cognitive functions.

Also, Hezareie et al. (2013) displayed the effectiveness of CBT treatment in improving the reaction time of the samples (Hezareie, Rasoolzade, Moradi, \& Ebrahimabad, 2013).

With respect to the indices of "completed classes" and "preservation error," we found that subjects" performance was significantly better in both experimental groups compared to the control group. Even so, although the performance of combined treatment group was slightly better than the medical treatment group, this did not reveal a significant difference. With regard to the three indices of "other errors," "failure to maintain a sequence," and "attempt to complete the first pattern," it was demonstrated that both combined treatment and medical treatment had a significant effect, compared to the control group, in enhancing subjects' performance. Combined treatment had a significantly better impact than medical treatment in this regard as well. The result of this part of the study is consistent with the research by Fazeli et al. (2015) that confirmed the effect of cognitive-behavioral therapy on cognitive flexibility. In order to achieve cognitive flexibility, one must understand the complexity of the problem and frequently examine the problem, which requires a higher level of cognition, and mostly a patient with interruption is unable to solve.

According to the results of this study, it seems that, in explaining the effectiveness of cognitive-behavioral therapy, training the skills of cognitive-behavioral therapy is helpful in terms of some executive functions such as attention, reaction time, problem-solving strategies, and control of impulsive behaviors; an objective that can be attained through improving cognitive functioning or increasing cognitive abilities of individuals involved. Given that cognitive functions can be seriously impaired due to apnea, one may compensate for the defects resulting from the disease by properly taking advantage of cognitive-behavioral treatment as a regular therapeutic activity built upon cognitive principles. This seems an important suggestion because frequent sleep apneas might damage the performance of central neural system and the implementation of many cognitive tasks. Thus, it is proposed that if one effectively learns cognitive control skills and sleep hygiene strategies, his neural system and cognitive performance will improve accordingly. This is due to the fact that one of the goals of cognitivebehavioral treatment is to make life style interventions so as to enhance recovery and increase cognitive performance.

Shiri et al. (2016) demonstrated that cognitivebehavioral therapy improves the health and quality of sleep in patients. In the same vein, in Mothghi's research (2016), cognitive-behavioral therapy improved the general quality of sleep in the elderly who showed signs of sleep disorder. Abdolahi et al. (2015) also proposed that CBT is effective in treating insomnia in patients.

Our research is comparable with Dastani et al's study (2011) which compared drug therapy and behavioral therapy in women with insomnia. Based on their findings, both psychological and medical interventions could improve sleep quality and insomnia. Comparison between the two kinds of interventions showed that psychological interventions are more effective than medical intervention.

Although CBT treatment basically focuses on changing the content of thought and cognitive processes, practically the major emphasis in our treatment was on a number of central issues related to patients' daily life such as sleep hygiene, emotional selfregulation, increasing cognitive flexibility, and controlling as well as coordinating behavior. 


\section{CONCLUSION}

The study revealed that both medical approach and combined treatment are effective in treating apnea symptoms. However, upon comparison, it was observed that the efficacy of combined treatment was significantly greater than medical treatment.

Indeed, despite the benefits of cognitivebehavioral therapy in improving sleep quality, sleep disorders are often addressed by physicians, and psychologists only occasionally deal with them. Notwithstanding the psychological complications of this disorder, seldom are sleep medicine specialists familiar with its methods of treatment. Thus, it appears that increasing the knowledge of specialists with regard to the efficacy of cognitive-behavioral methods

\section{References}

Abollahi, A., Nazar, A., Hasani, J., Darharaj, M., \& Behnam Moghadam, A. (2015). Effectiveness of Cognitive-behavioral Group Therapy on Insomnia Symptoms in Students. Armaghane danesh, 20(1), 11-18.

Ağargün, M. Y., Kara, H., \& Anlar, Ö. (1996). The validity and reliability of the Pittsburgh Sleep Quality Index. Turk Psikiyatri Derg, 7(2), 107-115

Alhola, P., \& Polo-Kantola, P. (2007). Sleep deprivation: Impact on cognitive performance. Neuropsychiatric disease and treatment, 3(5), 553.

Aloia, M., Arnedt, J., Stepnowsky, C., Hecht, J., \& Borrelli, B. (2005). Predicting treatment adherence in obstructive sleep apnea using principles of behavior change. Journal of clinical sleep medicine: JCSM: official publication of the American Academy of Sleep Medicine, 1(4), 346-353.

Bandura, A. (1989). Human agency in social cognitive theory. American psychologist, 44(9), 1175.

Bandura, A., \& Walters, R. H. (1977). Social learning theory.

Baran, A. S., \& Richert, A. C. (2003). Obstructive sleep apnea and depression. CNS spectrums, 8(02), 128-134.

Bardwell, W. A., Moore, P., Ancoli-Israel, S., \& Dimsdale, J. E. (2003). Fatigue in obstructive sleep apnea: driven by depressive symptoms instead of apnea severity? American Journal of Psychiatry, 160(2), 350-355.

Bourke, R., Anderson, V., Yang, J. S., Jackman, A. R., Killedar, A., Nixon, G. M., ... Horne, R. S. (2011). Cognitive and academic functions are impaired in children with all severities of sleepdisordered breathing. Sleep medicine, 12(5), 489-496.

Buysse, D. J., Reynolds, C. F., Kupfer, D. J., \& Thorpy, M. J. (1994). Clinical diagnoses in 216 insomnia patients using the International Classification of Sleep Disorders (ICSD), DSM-IV and ICD-10 categories: a report from the APA/NIMH DSM-IV Field Trial. Sleep: Journal of Sleep Research \& Sleep Medicine.

Dastani, M., Jomheri, F., FATHI, A. A., Sadeghniiat, K., \& Someloo, S. (2011). Effectiveness of drug therapy and behavioral therapy on chronic insomnia. and encouraging psychologists to cooperate with physicians at sleep clinics will lead to obtaining better results in treating sleep disorders. Besides, one may use this method in sleep clinics as a complement to medical treatment.

\section{Compliance with ethical standards}

Funding: The authors declared that this study received no financial support

Conflict of interest: The authors declare that they have no conflict of interest.

Ethical approval: The whole procedures on the human participants were approved by the Board of Ethics of the hospital and university.

Informed consent Oral informed consent was obtained from all the participants of the study.

Dorrian, J., Rogers, N. L., \& Dinges, D. F. (2005). Psychomotor vigilance performance: Neurocognitive assay sensitive to sleep loss. Marcel Dekker New York.

Durán, J., Esnaola, S., Rubio, R., \& Iztueta, Á. (2001). Obstructive sleep apnea-hypopnea and related clinical features in a population-based sample of subjects aged 30 to $70 \mathrm{yr}$. American journal of respiratory and critical care medicine, 163(3), 685-689.

Engleman, H. M., Asgari-Jirhandeh, N., McLeod, A. L., Ramsay, C. F., Deary, I. J., \& Douglas, N. J. (1996). Self-reported use of CPAP and benefits of CPAP therapy: a patient survey. Chest, 109(6), 1470-1476.

Engleman, H. M., \& Wild, M. R. (2003). Improving CPAP use by patients with the sleep apnoea/hypopnoea syndrome (SAHS). Sleep medicine reviews, 7(1), 81-99.

Espie, C. A., Inglis, S. J., \& Harvey, L. (2001). Predicting clinically significant response to cognitive behavior therapy for chronic insomnia in general medical practice: Analyses of outcome data at 12 months posttreatment. Journal of Consulting and Clinical Psychology, 69(1), 58.

Fazeli, M., Ehteshamzadeh, P., \& Hashemishabani, E. (2015). The Effectiveness of Cognitive-Behavioral Therapy on the Cognitive Flexibility of Depressed People. Thought and behavior in clinical psychology, 9(34), 27-36.

Findley, L. J., Barth, J. T., Powers, D. C., Wilhoit, S. C., Boyd, D. G., \& Suratt, P. M. (1986). Cognitive impairment in patients with obstructive sleep apnea and associated hypoxemia. CHEST Journal, 90(5), 686-690.

Gagnon, K., Baril, A.-A., Gagnon, J.-F., Fortin, M., Decary, A., Lafond, C., ... Gosselin, N. (2014). Cognitive impairment in obstructive sleep apnea. Pathologie Biologie, 62(5), 233240.

Golay, A., Girard, A., Grandin, S., Métrailler, J.-C., Victorion, M., Lebas, P., .. . Rochat, T. (2006). A new educational program for patients suffering from sleep apnea syndrome. Patient education and counseling, 60(2), 220-227. 
Hezareie, D., Rasoolzade , K., Moradi, A., \& Ebrahimabad, A. (2013). (Comparison of the Effectiveness of Cognitive Behavioral Therapy (CBT) and Behavioral Activation Therapy (BAT) in Reforming Cognitive Performance (Working Memory and Simple Reaction Time (SRT)) of heroin abusers in Afghanistan. Cognitive psychology, 1.

Incalzi, R. A., Marra, C., Salvigni, B. L., Petrone, A., Gemma, A., Selvaggio, D., \& Mormile, F. (2004). Does cognitive dysfunction conform to a distinctive pattern in obstructive sleep apnea syndrome? Journal of sleep research, 13(1), 79-86.

Iranzo, A., \& Santamaria, J. (2005). Severe obstructive sleep apnea/ hypopnea mimicking REM sleep behavior disorder. Sleep, 28(2), 203-206.

Lal, C., Strange, C., \& Bachman, D. (2012). Neurocognitive impairment in obstructive sleep apnea. CHEST Journal, 141(6), 1601-1610.

Lindberg, E. (2010). Epidemiology of OSA.

Lojander, J., Kajaste, S., Maasilta, P., \& Partinen, M. (1999). Cognitive function and treatment of obstructive sleep apnea syndrome. Journal of sleep research, 8(1), 71-76.

McFadyen, T., Espie, C., McArdle, N., Douglas, N., \& Engleman, H. (2001). Controlled, prospective trial of psychosocial function before and after continuous positive airway pressure therapy. European Respiratory Journal, 18(6), 996-1002.

Flemons, W. W., Buysse, D., Redline, S., Oack, A., Strohl, K., Wheatley, J., ... \& Fleetham, J. (1999). Sleep-related breathing disorders in adults. Recommendations for syndrome definition and measurement techniques in clinical research. Sleep, 22, 667-689.

Meyer, J. S., Sakai, F., Karacan, I., Derman, S., \& Yamamoto, M. (1980). Sleep apnea, narcolepsy, and dreaming: regional cerebral hemodynamics. Annals of neurology, 7(5), 479-485.

Mohlman, J., \& Gorman, J. M. (2005). The role of executive functioning in CBT: a pilot study with anxious older adults. Behaviour research and therapy, 43(4), 447-465.
Morin, C., Blais, F., \& Savard, J. (2002). Are changes in beliefs and attitudes about sleep related to sleep improvements in the treatment of insomnia? Behaviour research and therapy, 40(7), 741-752.

Mottaghi, R., Kamkar, A., \& Maredpoor, A. (2016). Effectiveness of Cognitive Behavior Therapy on the Quality of Sleep in Elderly People With Insomnia Disorder. Iranian Journal of Ageing, 11(2), 234-243.

Nejati, V., Zabihzadeh, A., \& Nikfarjam, M. (2012). The relationship between mindfulness and sustained and selective attention functions. Journal of Cognitive and Behavioral Sciences, 2(2).

Richards, D., Bartlett, D. J., Wong, K., Malouff, J., \& Grunstein, R. R. (2007). Increased adherence to CPAP with a group cognitive behavioral treatment intervention: a randomized trial. SLEEPNEW YORK THEN WESTCHESTER-, 30(5), 635.

Saunamäki, T., \& Jehkonen, M. (2007). Depression and anxiety in obstructive sleep apnea syndrome: a review. Acta Neurologica Scandinavica, 116(5), 277-288.

Sharafkhaneh, A., Giray, N., Richardson, P., Young, T., \& Hirshkowitz, M. (2005). Association of psychiatric disorders and sleep apnea in a large cohort. SLEEP-NEW YORK THEN WESTCHESTER-, 28(11), 1405.

Sharafkhaneh, A., Richardson, P., \& Hirshkowitz, M. (2004). Sleep apnea in a high risk population: a study of Veterans Health Administration beneficiaries. Sleep medicine, 5(4), 345-350.

Shiri, S., Sh, B., Gh, S. F., \& Ahadi, H. (2016). Effectiveness of multicomponent cognitive behavioral intervention on quality of sleep and general health in drug abusers. J Qazvin Univ Med Sci. 2016; 20 (4): 29-35. Corresponding Address: Shokoh Sadat Banijamali, Alzahra University, Psychology Group, Tehran, Iran Email: banijamalishoko@ yahoo. com Tel, 98-912.

Tyrrell, J., Poulet, C., Pe, J.-L., \& Veale, D. (2006). A preliminary study of psychological factors affecting patients' acceptance of CPAP therapy for sleep apnoea syndrome. Sleep medicine, 7(4), 375-379. 